\title{
Urology Education and the Demand of Social Development Jin-guo WANG ${ }^{1, a}$ and Na WANG ${ }^{2, b,{ }^{*}}$ \\ ${ }^{1}$ Department of Urology, the First Hospital of Jilin University, China \\ ${ }^{2}$ Department of Anesthesiology, the First Hospital of Jilin University, China \\ âwangjinguolily@163.com, bwangna080613@163.com \\ ${ }^{*}$ Corresponding author
}

Keywords: Medical education, Urology, Social development, Social Requirement.

\begin{abstract}
Urology is a medical science about the diseases of the urogenital system, improving the quality of health care and treatment of diseases. With the rapid development of the society, the knowledge structure and the types of disease are constantly changing urological teachers shall explore teaching methods to adapt to the social demand. Cultivating the student's communicating ability is also becoming more and more important.
\end{abstract}

\section{Introduction}

The connotation of the development of modern medicine, the urinary surgery from pure period extended to individual health for disease control and prevention and health involves all the problems. Urology medical education have someone a new era, namely, group and individual, global and local, all sorts of physical and psychological content in urological surgery teaching process should be organically combined and carry out. Therefore, urological surgery education workers facing the constantly update the knowledge structure explore the surgical department teaching ways and methods of the medical education to adapt to the needs of society the enormity of the task. Along with the social progress, economic development and the change of environment, great changes have taken place in the disease. Medical model must change to adapt to these changes [1]. Therefore, the surgical department of medical education idea, the overall structure and content, also need to make corresponding adjustment. This review of urological surgeons practice ability, added more comprehensive factors.

\section{The Position and Characteristics of Urology in Clinical Medical Education}

Urinary surgery as a clinical medical theory and the important part of medical practice already contains the basic content of internal medicine, and surgery inseparable, is more closely related to obstetrics and gynecology. Most importantly, urological surgery always runs through individual growth and development of composition and the main line, make it become the most closely relationship with the individual age and physical changes of clinical medicine [2]. At present, the medical education in the allocation of clinical course, urological surgery proportion is not high. The class hour distribution puts forward higher requirements for urological surgery teaching. Medical undergraduate students, on the basis of science and surgery to learn, through the study of urinary surgery again, they can have a fair degree of urological surgery basic theories and skills. Only familiar with the normal development rule, to determine the normal and abnormal, timely find deviation, thus recourse causes illness. Urinary surgery teaching 
difficulty lies in the teacher individual these special points must be embodied in the whole teaching process of urinary surgery.

\section{New Challenges of Urological Education}

The development of medical science, it is imperative to reform the medical education. Under the overall reform of medical education objectives, urological surgery teachers will pursue and capture new knowledge on one hand, to meet the needs of the information age, to face the contemporary medical science information and knowledge in less than two years doubled the reality. On the other hand is devoted to the cycle of knowledge update. Basis in the 20th century, the development of science and engineering technology have leap, the results also has brought unprecedented opportunities for development of medical and expand the development of the vast empty [3].

Theory of molecular biology, engineering and gene engineering technology, for the further development of genetics and microbiology provides a guarantee. These, greatly promoted the clinical medical study, changed the clinician awareness of the disease. Therefore, the teacher in the new theory, new knowledge at the same time, also faces how these new theories, new knowledge to the teaching of the implementation of the problem. In today's rapid development of science and technology, has become more and more urgent to solve this problem. To make medical students to learn basic theories, basic knowledge and basic skills at the same time, through the teacher's teaching guide, teaching and students' self-study, understand the development of medical science frontiers [4]. On the other hand, teaching to the student's ability, self-study ability is becoming more and more important, in particular, centering on the problem of teaching method will occupies more and more important position in teaching.

Urinary surgery teaching in medical education is undoubtedly an important position. Urologists for urological surgery teaching, trying to teach students basic urological surgery of new theories, new knowledge at the same time, also taught about disease prevention knowledge and carry out community medical concept, including the basic knowledge of community service, etc. Therefore, they should not only solve the contradiction between time and content, and to solve the contradictions of cutting-edge knowledge and knowledge base. Therefore, urological surgery as one of the focus of the clinical medicine teaching, teaching reform should be and must actively.

\section{Suggestions to the Teaching of Urology}

At present, most of the medical colleges and universities teaching mode is based on the traditional patterns of the subject as the center between relatively independent curriculum, content cohesion sex differences. Students into a discipline study are the basic theory and the organic integration between clinical departments. Although they only have studied diagnostics based content in clinical, but in the face of the clinical departments, is still at a loss.

Therefore, the traditional medical education mode and teaching method reform, has become the most important current medical teaching reform one of the content. For the focus of the traditional medical education pattern reform, is to teach medical students in the classroom study and clinical practice, to know disease to the human body as a whole, sets up the system of a correct concept of clinical thinking, thus to make a correct diagnosis and treatment of disease [5]. Let the medical students set up the system of a 
correct concept of clinical thinking, is the key to cultivate qualified clinician. In terms of urinary surgery, teachers should provide more practice opportunities for medical students, to make medical students not to disease was confused about what to do. Therefore, reduce the large lecture class, increase the trainee class is one of the measures of the reform. Through years of urological surgery clinical teaching practice, puts forward the following suggestions for urological surgery teaching.

\section{Reform Lecture Teaching Mode of Urology}

Instructor should first clear lectures to achieve the purpose of his teaching. Achieve the purpose of teaching is to enable students to understand the urology surgery the main characteristics of each theory, and the thread a few of them, as a starting point, to a group of diseases to discuss, find out the inner rules of this group of diseases, and contact with other diseases;Pathological physiology as the main line, teach students to search possible clinical manifestations of disease, understand disease treatment, put an end to scripted way of classroom teaching.

Large course teaching content should let students know in advance. In this way, to stimulate and promote the teacher prepares a lesson's initiative and creativity, but also to a certain extent, change the teacher-centered, classroom as the center and textbook as the center of teaching mode, the teaching mode gradually shift towards the direction of the centering on the problem, to achieve from set out actually, fewer but better, attaches great importance to the induction and analysis of the mutual infiltration and related subjects, the purpose of comprehensive and students to set aside a certain space of thinking.More importantly, it can be heuristic, discussion-based teaching methods into the classroom, make classroom atmosphere active [6].

\section{Reform Urological Clinical Practice}

Must be "clinical" clinical teaching, clinical practice is a kind of implementation problems centered teaching method. Clinical practice questions from patients and instance.Students can ask the teacher with a problem. Clinical teaching is critical to the success of the teachers and students to participate on both sides. Clinical teaching, the teacher to let the students initiative, teachers in combination with the actual cases of complement of large course content, from set out actually, ask questions to let the students discuss, teachers avoid by all means is long, repeat the content of the lectures to teach. This can achieve the teaching point for the purpose of strengthening and deepening in practice.

The focus of the clinical practice is to make students master the diagnosis and treatment of common diseases and frequently-occurring disease, also want to let them understand rare disease and difficult diseases. Teachers should value in the clinical practice to cultivate students the correct clinical thinking ability. Attending physician rounds, lead students is the key to achieve this purpose. In the daily operation work, should help students to establish correct clinical thinking. At the same time, should also let the students know the latest progress in the field of related.

\section{The Teacher is the Key for the Teaching Reform}

The training of teachers can take focus and combination in the form of individual guidance. Teachers focus on training contents include: basic theories and knowledge of teaching and education training. Individual guidance is to point to make the teaching experienced teachers, to undertake a certain content of teaching teachers to empirical guidance. University has always insisted on young teachers teaching demonstration 
system, by the long engaged in teaching the teachers' comments, and young teachers communicate with each other, has achieved good teaching effect.

\section{Reform Evaluation System of Urology}

Due to the particularity of urologists profession, the test should be test at the same time the student to the memory must be urological surgery the master degree of knowledge and comprehensive analysis ability. After giving a lecture and trainee, we deal with students in the first stage of the written examination. After finish internship, must carry out the second phase of the interview. The first phase is drawn mainly from the computer-based exam questions, and then combined with the actual, in accordance with the appropriate increase or decrease in urinary surgery teaching outline examination content. The second phase, can take the oral exam form can examine the student to the processing capacity of patients, medical record analysis ability, etc. In short, the starting point of urological surgery teaching test should be on the test students' ability to solve practical problems.

\section{Strengthen Students' Communicating Ability}

Physician's ability to communicate more and more influence to the ability and effect of clinical disease, the levels of doctor-patient communication is directly related to the patients' confidence for physicians. For a long time, because our country's medical education to the cultivation of students' communication ability enough attention, leads to poor doctor-patient communication. Therefore, you should continue to increase the participation of students in urological surgery teaching, cultivate their ability of communication in practice, and this ability is one of the main indicators for evaluating the comprehensive ability.

Urinary surgery is developed by scientific development, especially the development of biological science strongly push. Urological surgery teaching teacher only by constantly update knowledge, pay attention to the progress of the world medical education, attaches great importance to the exercise and improve the teaching ability, in this way can we truly devoted to urinary surgery teaching reform, training more qualified for the society urologists.

\section{Summary}

To sum up, four specific objectives constitute medicine in the new goals, content is rich, and embodies the "people-oriented, to the patient as the center" concept, reflects the prevention health care as one of the goals. Clinical work is the basic knowledge, basic theory and basic skills together, forming a basic framework, add new knowledge, new progress in the field, thus causes the student to obtain the correct clinical thinking and knowledge of common disease diagnosis and treatment of frequently-occurring disease.

\section{References}

[1] Seguara JW. Endoccrology. Journal d Urologie. 1984

[2] Segura JW. Percuateous removal of kid ney stones review of 1000 aces. Journal d Urologie. 1985

[3] Keating MA, et al. Ureterscopy:the in itial experience. Journal d Urologie. 1986 
[4] Kutcher R, et al. Sonographically guided percutaneous renal interventional procedure. The Journal of The American Medical Association. 1984

[5] Huffman JL, et al. Entending cystoscopic techniquas into the ureter and ranal pelvis. The Journal of The American Medical Association. 1983

[6] Nelson RN, et al. Methodology for endoscopic treatment of ureteral calculi. Journal d Urologie. 1986 